Motrivivência $\quad$ Ano XXII, No 35, $^{\circ}$ P. 18-40 Dez./2010

doi: 10.5007/2175-8042.2010v22n35p18

\title{
DO TRABALHO EM GERAL AO TRABALHO PEDAGÓGICO: contribuição ao debate sobre o trabalho pedagógico na Educação Física
}

Celi Taffarel'

\section{RESUMO}

O texto trata do trabalho pedagógico na educação física considerando elementos da ontologia do ser social que nos permitem explicar como nos tornamos seres humanos ao longo da história e as características imanentes do trabalho. A pergunta científica diz respeito às possibilidades das mudanças nas tendências imanentes ao processo de trabalho capitalista em geral, em particular do trabalho pedagógico, e em especial, na educação física. A hipótese é de que não tem havido mudanças nas tendências imanentes do processo de trabalho capitalista, além das analisadas por Marx, o que nos coloca o desafio histórico de reconhecermos, no trabalho pedagógico, suas possibilidades e tendências, para nelas interferir. $\mathrm{O}$ fio condutor da exposição parte do conceito de movimento, matéria, atividade, trabalho e consciência, considerando determinados modos de produção - comunal, asiático, feudal, capitalista -, para chegarmos às possibilidades do trabalho em geral e, em especial, do trabalho pedagógico. Dados empíricos advêm da área da educação física e as fontes são as mediações no Curso de Licenciatura em Educação Física da UFBA. As análises realizadas estabelecem relações e nexos entre o movimento mais geral do capital e suas leis e as particularidades do trabalho pedagógico, em especial na educação física, indicando a atualidade da defesa do Curso Unificado de Licenciatura Ampliada.

Palavras-chave: Trabalho. Trabalho Pedagógico. Educação Física.

1 Professora Pesquisadora Nível 1 CNPq titular UFBA. Doutora em Educação. Especialista em Ciências do Esporte. Mestre em Ciências do Movimento Humano. Contato: celi.taffarel@gmail.com 


\section{Introdução}

Quem somos nós, de onde viemos? O que estamos fazendo aqui? Para onde vamos? Como nos tornamos seres humanos? Como a matéria adquiriu consciência de si mesma? É possível conhecer? Estas são perguntas filosóficas colocadas à humanidade desde que nos reconhecemos como seres humanos.

Como o movimento converte-se em matéria, em determinadas condições de tempo e espaço? Como a matéria fisica, em condições objetivas se transforma quimicamente: como a substância química se transforma biologicamente, em determinadas condições, adquirindo consciência de si mesma, de sua natureza e da natureza que a cerca?

Como, portanto, pela atividade de intercâmbio com o meio que a cerca, a matéria viva passa a conhecer as propriedades do que a cerca e, no processo de intercâmbio com a natureza, a transforma, transformando-se a si mesma? Como esta matéria viva passa a conhecer e transformar as condições de sua existência e a produzir a cultura? Como esta cultura, transformada, é assegurada de uma geração para a outra, configurando modos de produção da vida? Como, por saltos qualitativos, os modos de produção da vida vão sendo transformados?
Como estas formas de existência da matéria, que possuem movimento, extensões e dimensões, entram em conflito, em confronto, em contradições, desenvolvendo assim a própria matéria e a consciência?

Como a matéria inorgânica, em luta de forças contrapostas, é capaz de atrair e de repulsar outras matérias?

Como nos organismos vivos a assimilação e desassimilação condicionam o crescimento?

Como no desenvolvimento social as contradições se estabelecem entre as forças produtivas e as relações de produção?

Que leis gerais regem estes processos? Como compreendê-los?

Uma dessas leis, definida após ser encontrada a regularidade desses processos mecânicos, físicos, químicos, biológicos e sociais é a lei geral da unidade e da luta dos contrários. É uma das leis fundamentais da dialética materialista histórica.

A outra lei, encontrada na busca das regularidades dos fenômenos mecânicos, físicos, químicos, biológicos e sociais é a lei da passagem das mudanças quantitativas e qualitativas, e vice-versa, enquanto lei do desenvolvimento da natureza. Esta lei se manifesta tanto nas mudanças das substâncias físicas, químicas, biológicas e sociais. 
Outra lei geral encontrada na busca de regularidades destas transformações é a negação que permite a transformação do velho em algo novo. Quando são conservados aspectos positivos do desenvolvimento, este adquire o aspecto de progresso. Em caso contrário, adquire aspecto degenerativo e destrutivo. Este desenvolvimento, pela negação da negação, se dá em espiral com a repetição, em estágios superiores, de aspectos e traços isolados dos estágios inferiores.

Com base nessas leis vamos nos perguntar sobre a vida social. O que é a sociedade humana? Quais as leis de seu desenvolvimento? Como conhecê-las e utilizá-las?

$\mathrm{Na}$ vida social, portanto, atuam leis gerais e objetivas, independente de nossa vontade e que subordinam os acontecimentos sociais. Portanto, conhecer essas leis, empregá-las a favor da vida foram desafios que a humanidade se colocou e para tanto desenvolveu, pelo trabalho humano, a ciência. O trabalho humano tem, portanto, esse caráter geral, fundante do ser social.

Se nos primórdios da humanidade esse processo de desenvolvimento social se dava com base no conhecimento empírico, sensitivo, com o desenvolvimento dos modos de produção da vida - nos modos comunal, asiático, feudal, capitalista -, avançamos nas nossas funções psíquicas e nos instrumentos para conhecer.

Superamos as fases em que prevaleciam as leis biológicas e passamos a viver sob leis sóciohistóricas. Superamos as fases em que nada sabíamos, a fase em que o que sabíamos era de domínio de poucas autoridades, religiosas, feudais, filosóficas e avançamos para um modo especial de conhecer que é o conhecimento cientifico, decorrente de da investigações criteriosas, rigorosas, sistemáticas.

Portanto, pelo movimento cria-se o material, que pela atividade cria a vida, que pela vida, e nela o trabalho humano, cria as sociedades. Para conhecer a sociedade, portanto, conhecer o seu grau de desenvolvimento, sua cultura, é necessário recuperar esses elementos ontológicos do ser social.

Para compreender as leis gerais que regem as sociedades $\mathrm{e}$ compreender como elas determinam a consciência é necessário tratar do elemento fundante da sociedade, e este é, portanto, o trabalho.

O trabalho não significa somente uma ação humana. É muito mais do que isto. É um ser humano, com suas condições físicas, químicas, biológicas, psicológicas e sociais que realiza um intercâmbio com a natureza, transformando-a e sendo transformado por ela, gerando a 
cultura. O trabalho, portanto, que é elemento fundante do ser social, vai adquirindo ao longo da história características, mantendo, no entanto, o que lhe é imanente.

\section{Desenvolvimento}

Sem entender o trabalho em geral e as características que o mesmo assume no modo de produção capitalista, não vamos compreender o trabalho pedagógico na escola e muito menos o trabalho pedagógico na Educação Física.

O processo de trabalho

"O primeiro pressuposto de toda a história humana é naturalmente a existência de indivíduos humanos vivos" (MARX, 1987, p.27). E para se manter vivo, teve o homem que produzir seus meios de vida, meios esses que foram sendo modificados no curso da história, pelas ações dos próprios homens, em contato com a natureza, com os outros homens e consigo mesmo. Essa produção dos meios de vida, que tanto gera bens materiais quanto espirituais, se deu com base no trabalho humano ${ }^{2}$.

O trabalho é uma condição da existência humana, independentemente de qual seja a forma de sociedade. Ainda segundo Marx (1987), o trabalho é uma necessidade que medeia o metabolismo entre o homem e a natureza e, portanto, o da própria vida humana. O processo de trabalho é uma condição da existência humana; é comum a todas as formas de sociedade, mas se diferencia pelas relações sociais estabelecidas.

O trabalho útil ou trabalho concreto é uma atividade produtiva de um determinado tipo, que visa a um objetivo determinado; seu produto é um valor de uso. O trabalho abstrato, ou trabalho socialmente necessário, por sua vez, é o dispêndio de força de trabalho humana que cria valor, mas com aspecto diferente. Está relacionado com a medida quantitativa do valor, pois determina a magnitute do valor, e está relacionado com o tempo de trabalho socialmente necessário à produção de um produto.

O trabalho útil, concreto, e o trabalho abstrato ou socialmente necessário são, portanto, uma mesma atividade considerada em seus aspectos diferentes. Ao desenvolver esta conceituação, Marx leva em conta que o trabalho abstrato é uma abstração social, um processo social real bem específico do capitalismo.

O processo de trabalho é aquele em que o trabalho é materializado em valor de uso, resultante

2 Explicações sobre o processo de "hominização" nesta perspectiva são tecidas por Engels, em escrito de 1876, "Humanização do macaco pelo trabalho" (v. ENGELS, 1990). 
da interação entre as pessoas e a natureza, ocorrendo aí modificações com base em propósitos humanos.

Constituem elementos do processo de trabalho: o trabalho em si, enquanto atividade produtiva com um objetivo; os objetos ou processos sob os quais o trabalho é realizado; e os meios que facilitam o processo de trabalho.

Todo o produto do trabaIho que entra no processo de troca converte-se em mercadoria. Tudo o que o homem produz, inclusive sua própria força de trabalho, para gerar algo, é mercantilizado, pois no processo de trabalho isto passa a ser trocado por outras mercadorias.

Portanto, a mercadoria é a forma que os produtos, resultantes do trabalho humano, assumem quando a produção é organizada por meio da troca. A mercadoria assume valor de uso por satisfazer alguma necessidade humana e adquire também um valor de troca por obter, por seu intermédio, outra mercadoria que serve como valor de uso.

O trabalho converte-se em valor de troca tornando-se na única "mercadoria" de uma parcela dos homens vendida por salários (MARX, 1989, p.41-93).

Entre os produtos que o trabalho do homem é capaz de gerar, existem aqueles que são produtos materiais, que se integram à lógica do valor de troca e se transformam em mercadoria nas relações sociais capitalistas. Mas existem também os produtos não-materiais que não se conformam facilmente à lógica capitalista de valor de troca. Encontramos aí os produtos que são consumidos no ato da produção, como o é a aula de um professor. A aula é um tipo de produto não material, que se consome no ato de produção, e que, apesar das resistências, está sujeito ao processo de mercantilização, sofrendo alterações em suas qualidades mais intímas (MARX, 1983).

Ao analisar o processo de trabalho, Marx (1989, p.201) deixa evidente que a utilização da força de trabalho é o próprio trabalho, e que a força de trabalho em ação é o próprio trabalhador que vai reaparecer em forma de mercadoria, mercadoria esta trocada por salários com os quais o trabalhador obtém seus meios de subsistência.

Portanto, em troca dos meios de subsistência, o trabalhador vende sua força de trabalho. Esta, além de pagar a si mesma, agrega valor à mercadoria durante o processo de produção, aumentando o seu valor de troca.

Esta forma específica de apropriação dos resultados do trabalho excedente não-pago, ou seja, sem que um equivalente seja dado em troca, é a extração da mais-valia, que é a forma específica que assume a exploração no modo de produção 
capitalista. É o processo de objetivação do trabalho não-pago (MARX, 1983). É a etapa da evolução socioeconômica em que a exploração não ocorre mais de forma grosseira da apropriação de homens através da escravidão ou servidão, mas na forma de apropriação do trabalho - etapa em que o trabalhador não é condição de produção mas somente o seu trabalho, que é apropriado por meio de troca.

A força de trabalho é, portanto, na sociedade capitalista, uma mercadoria, mas é uma mercadoria especial, visto que cria valores. Enquanto fonte de valor, gera valor maior do que ela própria possui.

E para ampliar ao máximo as possibilidades desta fonte de valor, o capital se desenvolve e se mantém enquanto relações econômicas e sociais, engendrando formas para a sua perpetuação, segundo suas próprias leis ${ }^{3}$.

A vida humana é, pois, uma produção social, que se dá pelo estabelecimento de relações sociais necessárias e independentes da vontade dos homens, relações que correspondem a uma determinada fase de desenvolvimento das forças produtivas materiais.

O conjunto destas relações de produção constitui a estrutura econômica da sociedade, a base concreta sobre a qual se eleva uma superestrutura jurídica e política, e à qual correspondem determinadas formas de consciência social. O modo de produção da vida material condiciona o desenvolvimento da vida social, política e intelectual em geral (MARX, 1983, p.24-5).

Este pressuposto nos aponta para a questão das relações sociais presentes em todos os âmbitos da vida humana, especialmente a nível das instituições educacionais, e do que lhes compete enquanto instâncias de produção e apropriação do conhecimento historicamente acumulado. Aponta-nos, ainda, para questões relacionadas com a formação social da mente (VYGOTSKY, 1988). O fundamento básico deste pressuposto é o de que os processos psicológicos superiores são mediados pela linguagem (semânticos) e estruturados não em localizações anatômicas fixas no cérebro, mas em sistemas funcionais, dinâmicos e historicamente mutáveis. O ser humano está, portanto, sujeito a determinações históricas no desenvolvimento de seus processos psicológicos superiores, dando-se isso pelas possibilidades

3 Uma das formas de perpetuação é a divisão do trabalho. Critícas concisas são apresentadas por Marglin, em Origem e função do parcelamento das tarefas (para que servem os patrões?) (In: GORZ, 1989). 
a ele colocadas e mediadas pela linguagem - linguagem que é uma das possibilidades de objetivação, de realização do ser humano.

A análise que Marx faz das relações que os homens estabelecem entre si, como resultado da especialização do trabalho e da divisão social do trabalho, permitenos reconhecer as formas que esta relação assume progressivamente, e as correspondentes formas distintas de propriedade que surgem. Permite-nos reconhecer, ainda, a culminação desse processo na separação entre o trabalho livre e as condições objetivas de sua realização; na separação entre os meios de trabalho e o objeto de trabalho; na separação do trabalhador do processo de trabalho, reduzindo-o a simples força-de-trabalho; na separação total entre o uso, a troca e a acumulação; na separação entre trabalho industrial, comercial e agrícola; na separação entre a cidade e o campo; na separação entre projetar e executar, enfim, na separação entre teoria e prática.

Esse processo que é histórico gera a alienação, que é uma categoria filosófica, sociológica e psicológica, que expressa a transformação objetiva da atividade do homem e de seus resultados em uma força independente, que o domina e lhe é contrária, e que expressa, também, a correspondente transformação do homem de sujeito ativo em objeto do processo social. Transforma-se o homem em objeto da história, limitando suas possibilidades de "ser sujeito". Exemplo clássico disso é a subsunção do trabalho humano ao capital, capital que é gerado pelo trabalho humano, ampliado pela extração da maisvalia e que torna-se estranho ao trabalhador. Temos aí os processos de trabalho que, cada vez mais, alienam o trabalhador de seu próprio trabalho e do fruto de seu trabalho. Temos aí a propriedade gerada socialmente e distribuída particularmente. Temos aí os bens culturais gerados social e coletivamente, mas acessíveis por poucos, com acesso privado, estando a maioria alienada do fruto de seu trabalho, do fruto de sua produção.

Mas, além de alienar de si mesmo seus próprios produtos, o homem se aliena de si próprio, da atividade mesma pela qual esses produtos são criados, da natureza na qual vive e dos outros homens. Isso tudo são aspectos da mesma coisa, ou seja, aspectos do processo de alienação do homem de sua "essência", de sua "natureza" e de sua humanidade, no modo capitalista de produção das relações sociais.

Existem muitas formas pelas quais o homem aliena de si mesmo os produtos de sua atividade 
e faz deles um mundo de objetos separados, independentes e poderosos, com os quais se relaciona como um escravo, impotente e dependente. Nesse processo, os objetos e as relações acabam assumindo certas características que Ihes são conferidas pelas relações sociais dominantes, mas que Ihe parecem pertencer naturalmente. Esse é o fetichismo que impregna as relações de produção da vida no modo capitalista. O fetichismo é uma força real, não controlada pelos seres humanos mas que exerce poder sobre os homens. A ilusão do fetichismo brota da fusão da característica social com as suas configurações materiais. O fetichismo da mercadoria é o exemplo mais simples e universal do modo pelo qual as formas econômicas do capitalismo ocultam as relações sociais a ele subjacentes. Por exemplo, quando o capital e não a mais-valia é entendida como fonte de lucro. Temos aí a "aparência" objetiva das relações econômicas e sociais (o capital é que gera o lucro e não o trabalho), e que só pode ser revelada em sua essência pela análise teórica, pois ela nos permite identificar e organizar analiticamente o que está acontecendo em nossa volta, nos permite explicar essas situações e fatos e, mais ainda, nos dá pistas para intervenções consequentes.
Produção/apropriação do conhecimento e o processo de trabalho pedagógico

A educação lida, fundamentalmente, com o conhecimento que é produzido e apropriado nas relações humanas vitais, no processo de trabalho. É, pois, imprescindível, ao se analisar qualquer uma das dimensões possíveis da educação, ter em conta a unidade do conhecimento humano, inserindo-o no processo de formação do indivíduo e de sua objetivação como gênero humano (DUARTE, 1992). Esse indivíduo está inserido em determinadas relações sociais, onde se dá sua formação enquanto um ser genérico, que mesmo sendo construído no interior de tais relações, necessariamente não se limita a elas ou a elas se adapta. Esse indivíduo se objetiva enquanto gênero humano nas atividades vitais que são atividades histórico-sociais. Tais atividades vitais se objetivam na apropriação da natureza e nas relações sociais, produzindo e reproduzindo a vida e suas condições de existência. Essa apropriação se dá pelo conhecimento, que é uma objetivação da atividade humana nas suas relações de produção da vida, e constitui-se pela unidade sujeito-objeto.

Enquanto objetivação da atividade humana, o conhecimento 
é uma produção coletiva, inserida criativamente na história dos povos que, em diferentes épocas e em diferentes configurações sócioeconômicas, políticas e culturais, responderam de maneira específica aos desafios colocados para a formação humana.

Para responder aos desafios historicamente colocados, buscou o homem apropriar-se dos meios que garantissem as condições de produção e reprodução de sua vida. E o fez mediatizado pelo "conhecer". Este conhecer pode ser reconhecido na história do conhecimento por suas várias formas de materialização.

Encontramos o conhecimento em sua forma mística, mítica, do senso comum, filosófico e científico; o conhecimento em suas formas perceptivas primárias (DAVYDOV, 1982), o conhecimento cientificamente elaborado (KOSIK, 1976) e o conhecimento em sua forma popular e erudita (CHAUI, 1990).

Dentro destas possibilidades encontramos ainda, diferentes perspectivas de sistematização e explicação para as formas que as lógicas de conhecimento assumem, o que nos remete a reconhecer os paradigmas clássico e contemporâneo, os paradigmas da filosofia analítica, do racionalismo crítico, da fenomenologia, da dialética materialista histórica, ou outras sistematizações que podem ser assumidas.
O grande embate sobre a produção e apropriação do conhecimento, segundo Lenine (1982), está colocado nas formas reacionárias do idealismo e na base teórica marxista, o que também é reconhecido por Cheptulin (1982), em suas análises das tendências materialistas e idealistas que descrevem e explicam esse processo complexo.

Estamos delimitando a abordagem dessa questão complexa à produção e apropriação do conhecimento científico no âmbito escolar e, ainda, recorrendo a têndencias explicativas materialistas, pois as mesmas levam em conta a formação material, onde o conhecimento é produzido e apropriado.

Ao privilegiarmos a questão da produção e da apropriação do conhecimento, enquanto elemento mediador no processo de formação/sociabilização via escolarização, temos que ter em conta três dimensões relacionadas à compreensão do conhecimento. Uma que diz respeito à produção, difusão , acesso e socialização do conhecimento culturalmente produzido e historicamente acumulado (LENI$N E$, 1982). Outra que diz respeito à apropriação do conhecimento pelo sujeito, destacando-se aí o ato cognoscitivo de elevar o pensamento do abstrato ao concreto, o que nos remete a ter em conta o método de pensamento (KOSIK, 1976). E 
ainda, uma outra que diz respeito à apreensão do conhecimento científico pela escola e sua organização, transmissão e avaliação através de conteúdos das matérias de ensino (DAVYDOV, 1982).

Estaremos privilegiando a formação do indivíduo (DUARTE, 1992) via escolarização, que se constrói pela objetivação e apropriação das relações sociais, dos conhecimentos e atitudes necessárias para a produção e reprodução do gênero humano. Essa educação se objetiva no ensino construído em condições objetivas contraditórias, dentro de possibilidades históricas em que estão em jogo interesses de classes antagônicas que determinam os rumos de tal processo. Esses rumos são expressos em projetos político-pedagógicos que objetivam a construção contraditória do processo de humanização e alienação do indivíduo.

Tendo como referência a teoria de Marx sobre o desenvolvimento econômico da sociedade, autores contemporâneos analisam as relações entre produção e apropriação social do conhecimento. Privilegiando o conhecimento científico e tecnológico, essas análises, segundo Sobral (1986, p.287-305), estabelecem relações sob três ângulos fundamentais, a saber:

a) a ciência e a tecnologia como força produtiva; b) a ciência e a tecnologia como dominação política;

c) a ciência e a tecnologia como ideologia.

A ciência e a tecnologia são reconhecidas como forças produtivas, porque sua incorporação no processo produtivo aumenta a produtividade do trabalho, produz mais-valia, assegurando a acumulação do capital e as condições que a perpetuam.

Elas são reconhecidas como dominação política pela sua incorporação à sociedade industrial avançada, assegurada pela existência de uma política de racionalidade científico-tecnológica assumida pelo Estado. Em suas análises das políticas públicas para a área de ciência e tecnologia Sobral (1986) confirma essa tendência singular, que expressa uma tendência geral do modo de produção capitalista.

O processo ensino-aprendiagem na escola

É no processo de ensinoaprendizagem que se dá a objetivação e apropriação, ou seja a formação humana. À educação interessa, em última instância, a formação humana, que se dá mediante a atividade social ativa do homem em suas relações com o meio, tranformando-o, atuando sobre o mesmo, enfim, trabalhando, 
modificando a realidade objetiva, sendo fundamental dentro dessa perspectiva a concepção objetiva de homem, pois o processo educativo é, em última instância, a formação humana.

O homem constrói-se homem histórico-concreto no conjunto das dinâmicas das relações sociais e das forças produtivas, numa determinada sociedade. Para que essa relação torne-se ativa e produtiva, é preciso que se assegure e se viabilize o acesso do homem à cultura material e espiritual acumulada historicamente, de modo a propiciar o desenvolvimento omnilateral, sendo esta a tarefa da educação e do ensino.

Constitui, portanto, a natureza do processo pedagógico o trato com o conhecimento, significando a conversão das ciências em materiais de ensino, a conversão do conhecimento científico em saber escolar, nos quais se incluem conhecimentos, atitudes e convicções inseridas em experiências sócio-culturais.

A força motriz do processo de ensino é a contradição entre o que é o aluno e as possibilidades do vir-a-ser, mediatizada pela produção e apropriação do conhecimento em seu sentido mais amplo. Essas tarefas compõem a atividade educativa que exige, segundo Duarte (1992, p.10), conhecer a concreticidade do aluno (indivíduo), o que ele é, bem como o que pode vir a ser, o que implica em posicionamento a favor de algumas - e, consequentemente, contra outras -, possibilidades desse vir a ser e em superação das formas alienadoras em que a objetivação e a apropriação possam se dar.

Partindo da referência de que a análise da organização do processo de trabalho pedagógico não prescinde de um exame da organização do mesmo na escola, e das relações que esta estabelece com a sociedade na qual está inserida, Freitas (1987) coloca, em primeiro plano, elementos a respeito da divisão do trabalho - característica imanente da sociedade capitalista e sua feição no aprofundamento da divisão do trabalho escolar, acentuado sob a inspiração tecnicista e com a introdução do gerenciamento científico na escola.

Ao analisar a organização do processo de trabalho pedagógico, Freitas (1987) faz referência ao gerenciamento científico na escola, que tem por base as mesmas premissas de sua introdução na indústria, a saber: a separação do processo de trabalho do trabalhador, a separação da concepção do trabalho de sua realização e o uso do monopólio do conhecimento do processo de trabalho para controle do trabalhador.

Acentuar essa divisão do processo de trabalho pedagógico, 
que pode estar conduzindo à proletarização do professor, é o esforço da vertente tecnicista, concentrada na elaboração, por parte de especialistas, de procedimentos didáticos, para gerar recursos instrucionais sofisticados, a serem usados pelos professores através de procedimentos "standartizados", ficando estes ausentes do processo de elaboração desses materiais, sendo pois, meros usuários.

Fica, assim, o professor afastado de sua especificidade planejar, executar e avaliar continuamente o processo de ensino -, estando essa didática presente no pensamento pedagógico brasileiro, nos cursos de formação de educadores e em muitos sistemas de ensino, sincronizando-se a concepção da organização do processo do trabaIho com a forma de gestão.

A gestão é, portanto, um dos pontos cruciais para afetar a organização do processo de trabalho pedagógico no interior da escola e da sala de aula, já que o problema não está apenas nos materiais instrucionais ou nos especialistas.

As mudanças das relações de trabalho no interior da escola serão construídas, portanto, pela criação de formas democráticas de gestão escolar, principalmente na perspectiva da participação ampliada da comunidade interna e externa na condução da escola.
A introdução de novas formas democráticas de gestão escolar facilitará e estimulará alternativas didáticas com repercussões na organização do trabalho pedagógico em sala de aula.

Outra categoria importante, no que diz respeito à organização do trabalho pedagógico na sala de aula, é a avaliação, por expressar relações de poder, e por modular o acesso aos conteúdos, interferindo no método. É pela avaliação formal e informal que a atual organização do trabalho pedagógico da sala de aula se impõe de forma autoritária.

No que diz respeito ao processo de trabalho pedagógico em sala de aula, Freitas (1991) argumenta que:

A organização do processo de trabalho pedagógico da escola como um todo, constitui-se, hoje, em uma grande trava para as mudanças de conteúdo, método e objetivos da escola, porque ela encarna as necessidades da organização capitalista que atribui à escola uma função social seletiva e preparatória para as relações sociais de produção capitalista. Esta organização do trabalho pedagógico da escola como um todo, é apoiada (e ao mesmo tempo apóia) pela organização do trabalho em sala de aula (...) onde os objetivos, métodos e conteúdos são categorias 
que organizam a sala de aula e estão perpassados por relações de poder que se sustentam a partir das práticas de avaliação do professor (...) relações que são uma antecipação na escola, das relações de poder no interior da fábrica. (FREITAS, 1991, p.121).

Para buscar novas bases de organização do trabalho pedagógico na sala de aula, de modo a ultrapassar o questionamento dos métodos para dar conta dos problemas das finalidades do ensino, de modo a enfrentar a contradição entre a necessidade de criar um novo tipo de homem e as formas da educação tradicional, e de modo a reconhecer que o fundamental nas instituições decorre muito mais de uma prática não verbalizada do que do conjunto de enunciados solenes de que ela se faz porta-voz, Pistrak (1981) propõe um conjunto de enunciados para alterar a escola.

Dentre esses enunciados destacamos, no presente estudo, a aplicação do "princípio da pesquisa" ao trabalho escolar o que significa que o conteúdo do ensino consiste em armar o educando para a luta e a criação de uma nova sociedade, compreendendo-se o que é preciso construir, e de que maneira é necessário fazê-lo, valorizando-se o trabalho coletivo e formas organizacionais eficazes, sendo o conhecimento do real e a auto-organização do coletivo escolar os elementos fundamentais de uma escola inserida na luta pela criação de novas relações sociais. Isso implica que a ciência deve ser ensinada como meio para conhecer e transformar a realidade, permitindo que os alunos "se apropriem solidamente dos métodos científicos fundamentais para analisar as manifestações da vida" (PISTRAK, 1981, p.95).

Este enunciado implica na compreensão de que "sem teoria pedagógica revolucionária, não poderá haver prática pedagógica revolucionária"; implica na compreensão de que a teoria marxista deve guiar a prática escolar, sendo esta expressa numa sólida pedagogia social; e implica ainda, que o professor assuma os valores de um militante social ativo e não um mero ser esmagado pelo peso de noções escolásticas, que impede a aptidão para a criatividade pedagógica (op. cit., p.29-31).

\section{Conclusão}

A questão pedagógica que nos colocamos é a de como podem ser considerados atualmente, no modo de produção capitalista, esses enunciados pedagógicos? Essa consideração é possível à medida em que reconhecemos a continuidade 
dialética e revolucionária do novo, que nasce do antigo graças às suas contradições internas.

A posição de Pistrak leva em consideração dois princípios fundamentais para a escola: a relação com a realidade atual e a autoorganização dos alunos.

O caráter do ensino, dentro do princípio da relação com a realidade, indica como objeto da educação a reflexão pedagógica do aluno necessária à compreensão e à explicação da realidade atual. Deduz-se daí o caminho da unidade metodológica - estudando-se os fenômenos em suas relações, demonstrando-se que os fenômenos que estão acontecendo são partes de um processo inerente ao desenvolvimento histórico geral, o que torna-se possível na medida em que o ensino se concentre em torno de grupos de fenômenos constituídos em objetos de estudo.

Quanto à auto-organização dos alunos - ao seu desenvolvimento enquanto coletivo que participa da gestão escolar, responsável pelo projeto político-pedagógico da escola - coloca-se a questão pedagógica do tipo de homem que é exigido pela fase de luta e construção em que vivemos atualmente, o que implica na compreensão clara, de cada membro da sociedade, sobre o que é preciso construir e como é preciso construir?
Essas contribuições evidenciam a necessidade de analisarmos a organização do trabalho pedagógico a partir de problemáticas significativas e relevantes, como o são a definição de um projeto histórico alternativo, a democratização das relações de poder, a configuração coletiva de um projeto político-pedagógico que envolva trabalho coletivo, unidade metodológica, auto-organização dos alunos e trabalho vivo, como eixo fundante e organizador curricular.

Em síntese, Pistrak evidencia como os fatores externos à escola penetram e permeiam fatores internos ao processo de trabalho pedagógico.

Podemos reconhecer essa interpenetração na contradição colocada à educação em geral que, por um lado, é imprescindível ao desenvolvimento da humanidade, mas, por outro, se desenvolve dentro dos limites da organização do processo de trabalho do modo de produção capitalista.

Indicadores dessa contradição são apontados nas análises sobre a formação do profissional do ensino nas licenciaturas em geral, onde destacamos uma série de problemáticas como: a desarticulação entre o processo de formação nas licenciaturas e o ensino de primeiro e segundo graus; a dicotomia entre teoria e prática; falta de produção 
do conhecimento e de investigação sistemática nos cursos; a segregação do conhecimento; a fragmentação e a divisão das áreas de conhecimento; a dicotomia entre licenciatura e bacharelado; fatores institucionais entravando o aprimoramento dos cursos.

Quanto à formação do profissional de Educação Física os estudos continuam indicando como problemáticas: a formação acrítica, a-histórica e a-científica; os currículos desportivizados (FENSTERSEIFER, 1987); a ênfase no paradigma da aptidão física com forte influência da área biológica, apesar de usarem terminologias como saúde e qualidade de vida. Contraditoriamente, não se evidencia a proximidade da área com as reivindicações colocadas nas licenciaturas em geral. A ênfase das preocupações curriculares recai na cientifização, ou seja, na busca do estatuto epistemológico da Educação Física e na formação via bacharelado.

Nos anos de 1990 a educação e mais especificamente a formação de professores em todas as áreas, dentre elas a Educação
Física, sofreu alterações. São elaborados e implementadas a Lei de Diretrizes e Bases da Educação (LDB - Lei 9394/96) e os Parâmetros Curriculares Nacionais (PCN, 1998) - respectivamente - que estão permeados pelas recomendações e orientações das políticas de cunho neoliberal ${ }^{4}$, direcionando assim os vários campos do saber como a própria Educação Física.

É nesse período histórico que os conservadores ganham força e em 1998, conseguem aprovar a lei que cria o primeiro Conselho Profissional privado do país, Lei 9696/98, o sistema CONFEF/CREF - Conselho Federal de Educação Física e Conselhos Regionais de Educação Física.

Em 1998, foi criada uma das Comissões de Especialistas em Educação Física para dirimir os problemas causados pela Resolução 03/87, como, por exemplo, a fragmentação da formação entre licenciatura e bacharelado. Em 2004, as Diretrizes Curriculares Nacionais para Graduação em Educação Física (DCNEF) foram aprovadas pela Resolução 07/04.

4 As políticas neoliberais na educação têm como um dos marcos, o ano de 1990, quando o Banco Mundial, juntamente com UNESCO, UNICEF, PNUD (Programa das Nações Unidas para o Desenvolvimento) lançaram a declaração mundial sobre "Educação para Todos", em Jomtien, Tailândia; Em 1994, em Brasília houve a "Conferência Nacional de Educação para Todos"; e devemos considerar que os Planos Decenais de Educação para Todos, prevêem metas a serem atingidas. Estas são de responsabilidade entre os governos federal, estadual e municipal em acordo nacional a partir da conferência nacional (TAFFAREL, 1997). 
O que nos fica evidente considerando as proposições de reformulações curriculares da Educação Física da década de 1930 aos anos 2000 é que ocorreu um processo de desqualificação do professor de Educação Física e essa desqualificação é mediada pela organização do trabalho pedagógico, com ênfase na dimensão do controle ideológico dos conteúdos e métodos. E isso é evidente nas propostas curriculares.

\section{Quadro 01: Reformulações Curriculares da Educação Física}

\begin{tabular}{|l|l|l|l|}
\hline Ano & Decreto/ Resolução & Modalidade & $\begin{array}{l}\text { Duração do } \\
\text { curso }\end{array}$ \\
\hline 1939 & Decreto-Lei 1212/39 & Licenciatura em Educação Física & 02 anos \\
\hline 1945 & Decreto-Lei 8270/45 & Licenciatura em Educação Física & 03 anos \\
\hline 1969 & Resolução 69/CFE/69 & Licenciatura em EF e Técnico Desportivo & 03 anos \\
\hline 1987 & Resolução 03/CFE/87 & Licenciatura e/ou Bacharelado em EF & 04 anos \\
\hline 2004 & Resolução 07/CNE/04 & Graduado em Educação Física & 04 anos \\
\hline
\end{tabular}

O que nos fica evidente analisando as propostas curriculares e os dispositivos legais é que continuam atuais as posições que não abandonam a análise das leis mais gerais do modo do capital produzir os bens materiais e imateriais, as leis que regem o estado burguês daí decorrente e suas relações de poder, as leis gerais da luta de classes decorrente da subsunção do trabalho ao capital que se expressa, não de maneira mecânica, mas, por mediações, na formação dos professores de educação física.

Uma das principais mediações é o trabalho pedagógico em geral e em especial o trabalho pedagógico da educação física.

Diante da desqualificação dos professores de educação física no processo de formação nos cursos de licenciatura e bacharelado, pelo controle ideológico do trato com o conhecimento, vale destacar a atuação do Movimento Estudantil da Educação Física (MEEF), que defendeu para a área da Educação Física uma formação única, a Licenciatura Ampliada, formação que segundo o MEEF amplia as possibilidades de intervenção por não restringir o campo de atuação e ainda, conforme os princípios em que se baseia, oferece melhores condições de formação. Diante do papel do CONFEF, que defende a fragmentação da formação na Educação Física principalmente sob o argumento dos diferentes campos de atuação, continua válida a defesa da formação em um único curso, 
sem fragmentação e divisão de conhecimentos.

Continuam atuais, portanto, as posições que defendem a unidade teórico metodológica na formação dos professores, a auto-determinação dos estudantes e a não divisão dos cursos em duas categorias que se diferenciam pelos campos de trabalho que atuam.

Afinal, tendo um objeto comum, a cultura corporal, uma essência de intervenção profissional comum, que é o trabalho pedagógico, o exercício da docência, o que justificaria a divisão na formação senão o controle ideológico, pela mediação do trabalho pedagógico, de trabalhadores alienados, para se manter a subsunção do trabalho ao capital?

\section{Referências}

ANDERSON, Perry. Considerações sobre o marxismo ocidental: nas trilhas do materialismo histórico. São Paulo: Boitempo Editorial, 2004.

BRASIL. Conselho Federal de Educação. Resolução $\mathbf{n}^{\circ} \mathbf{0 3}$, de 16 de Junho de 1987. Fixa os mínimos de conteúdo e duração a serem observados nos cursos de graduação em Educação Física (Bacharelado e/ou Licenciatura Plena). Diário Oficial da União, Brasília, DF, 10 set. 1987.
. Constituição da República Federativa do Brasil. Diário Oficial da União, Brasília, DF, 05 out. 1988.

. Lei de Diretrizes e Bases

da Educação Nacional n $^{\circ} \mathbf{9 . 3 9 4}$ de dezembro de 1996. Brasília: Câmara dos Deputados, 1996.

- Secretaria de Educação

Fundamental. Parâmetros Curriculares Nacionais: Educação Física /Secretaria de Educação Fundamental. Brasília: MEC/SEF, 1998.

. Lei $n^{\circ}$ 9.696, de $1^{\circ}$ de

setembro de 1998. Dispõe sobre a regulamentação da Profissão de Educação Física e cria os respectivos Conselho Federal e Conselhos Regionais de Educação Física. Diário Oficial da União, Brasília, DF, 2 set. 1998.

Parecer CNE/CP no 009, de 8 de abril de 2001. Diretrizes Curriculares Nacionais para a Formação de Professores da Educação Básica, em nível superior, curso de licenciatura, de graduação plena. Conselho Nacional de Educação, Brasília, 2001a.

\section{Parecer CNE/CEB $n^{\circ}$} 16/2001, de 03 de julho de 2001. Consulta quanto à obrigatoriedade da Educação Física como componente curricular da Educação Básica e sobre a grade curricular do curso de Educação 
Física da rede pública de ensino. Conselho Nacional de Educação, Brasília, DF, 2001b.

. Conselho Nacional de

Educação. Parecer $\mathbf{n}^{\circ}$ 0138, de 3 de abril de 2002. Diretrizes Curriculares Nacionais do Curso de Graduação em Educação Física. Câmara de Ensino Superior do Conselho Nacional de Educação, Brasília, 2002a.

. Projeto de Lei $\mathbf{n}^{0}$ 7.370, de 20 de novembro de 2002 . Acrescenta parágrafo único ao art. $2^{\circ}$ da Lei 9.696, de $1^{\circ}$ de setembro de 1998. Brasília: Câmara dos Deputados, 2002b. . Conselho Nacional de Educação. Parecer $\mathbf{n}^{0}$ 058, de 18 de fevereiro de 2004 . Diretrizes Curriculares Nacionais para os Cursos de Graduação em Educação Física. Câmara de Ensino Superior do Conselho Nacional de Educação, Brasília, 2004a. . Conselho Nacional de Educação. Resolução $\mathbf{n}^{0}$ 7, de 31 de Março de 2004. Institui as Diretrizes Curriculares Nacionais para os cursos de graduação em Educação Física, em nível superior de graduação plena. Câmara de Ensino Superior do Conselho Nacional de Educação, Brasília, 2004b.

- Conselho Nacional de Educação. Parecer CNE/CES $n^{\circ} 142 / 2007$, de 14 de junho de 2007. Alteração do $\S 3^{\circ}$ do art. 10 da Resolução CNE/ CES no 07/2004, que institui as diretrizes Curriculares Nacionais para os cursos de graduação em Educação Física, em nível superior de graduação plena. Câmara de Ensino Superior do Conselho Nacional de Educação, Brasília, 2007.

CARMO, Apolônio Abadio do. Educação Física, crítica a uma formação acrítica: um estudo das habilidades e capacidades intelectuais solicitadas na formação do professor de educação física. 1981. Dissertação (Mestrado em Educação) - Universidade Federal de São Carlos, São Carlos, 1981.

CHAUI, Marilena de Souza. Cultura e democracia: o discurso competente e outras falas. SP: Moderna, 1981.

. O que é ideologia. São Paulo: Brasiliense, 1984.

CHEPTULIN, Alexandre. Dialética Materialista: Categorias e leis da dialética. São Paulo: AlfaOmega, 1982.

COLETIVO DE AUTORES. Metodologia do ensino da Educação Física. São Paulo: Cortez, 1992.

CONSELHO FEDERAL DE EDUCAÇÃO FÍSICA. Resolução 045/02, de 18 de fevereiro de 2002. Dispõe sobre o registro 
de não-graduados em Educação Física no sistema CONFEF/ CREFs. Rio de Janeiro, Fev. 2002. Disponível em: <http:// www.confef.org.br $>$. Acesso em: 10 mar. 2009.

. Resolução $n^{0}$ 165/2008. Dispõe sobre a anuidade devida ao Sistema CONFEF/ CREFs. Disponível em: < http:// www.confef.org.br/extra/ resolucoes/ $>$. Acesso em: 24 abr. 2009.

Resolução $n^{\circ}$ 170/08, de 07 de novembro de 2008 . Dispõe sobre a publicidade da prestação de contas do exercício de 2007 do Conselho Federal de Educação Física. Disponível em: < http://www.confef.org.br/ extra/resolucoes/ $>$. Acesso em: 24 abr. 2009.

CRUZ, Amália Catharina Santos. Organização do trabalho pedagógico e currículo: realidade e possibilidades para a formação de professores a partir da experiência do projeto integrado universidade - rede pública de educação. 2006. Monografia (Especialização) - Faculdade de Educação, Universidade Federal da Bahia, Salvador, 2006.

. Organização do trabalho pedagógico e currículo: nexos lógicos e determinações históricas na formação de professores.
(Relatório Técnico-Científico PIBIC-FAPESB) Faculdade de Educação, Universidade Federal da Bahia, Salvador, 2003.

DAVYDOV, V.V. Tipos de generalización en la enseñanza. Cuba: Pueblo y Educación, 1982.

DIAS; Fernanda Braga Magalhães. A fragmentação da formação de professores de educação física: minimização da formação sob a ordem do capital. Dissertação (Mestrado). Programa de PósGraduação em Educação , UFSC, 2011.

DUARTE, Newton. (org.). Crítica ao fetichismo da individualidade. São Paulo: Autores Associados, 2004.

. Sociedade do conhecimento

ou sociedade das ilusões?: quatro ensaios crítico-dialéticos em filosofia da educação. São Paulo: Autores Associados, 2003.

ENGELS, Friedrich. A origem da família, da propriedade privada e do Estado. Rio de Janeiro: Editora Bertrand Brasil, 1991.

. O papel do trabalho na transformação do macaco em homem. In: ENGELS, F. O papel do trabalho na transformação do macaco em homem. 4 ed., São Paulo: Global, 1990.

. Ciência e ideologia na história: a situação do historiador marxista. In: FERNANDES, Florestan, (Org.). Marx-Engels: textos escolhidos. São Paulo: Editora Ática, 1989. 
ENGUITA, Mariano F. Tecnologia e Sociedade: a ideologia da racionalidade técnica, a organização do trabalho e a educação. In: Silva, Tomaz T. Trabalho, Educação e Prática social: por uma teoria da formação Humana. Porto Alegre: Artes Médicas, 1991.

A face oculta da escola. Educação e trabalho no capitalismo. Porto Alegre: Artes Médicas, 1989.

. Reprodução, contradição, estrutura social e atividade humana na educação. In: Teorias da Reprodução e da Resistência. Teoria e Debate. Porto Alegre: No 1: 109-133. nov/dez/1984.

ESCOBAR, Micheli Ortega. Transformação da didática: construção da teoria pedagógica como categorias da prática pedagógica: experiência na disciplina escolar educação física. 1997. 195 p. Tese (Doutorado em Educação) - Faculdade de Educação, Universidade Estadual de Campinas, Campinas, 1997. FENSTERSEIFER, Haimo $\mathrm{H}$. As teses equivocadas na formação do profissional de Educação Física e Desportos. In: CONGRESSO BRASILEIRO DE CIÊNCIA DO ESPORTE. 5. Recife, 1986 (mimeo).

FREITAS, Francisco Máuri de Carvalho. A sagrada família da
Educação Física. Vitória, ES: CEFD-UFES, 1997.

FREITAS, Helena Costa Lopes de. O trabalho como princípio articulador na prática de ensino e nos estágios. Campinas, SP: Papirus, 2007.

FREITAS, Luiz Carlos de. Crítica da organização do trabalho pedagógico e da didática. Campinas, SP: Papirus, 1995.

FREITAS, Luiz Carlos de. Projeto Histórico: ciência pedagógica e "didática". Educação e Sociedade. $n^{\circ} 27$, p. 122-140, 1987.

FRIGOTTO, Gaudêncio. (Org.). Educação e crise do trabalho: Perspectivas de final de século. Petrópolis, RJ. Vozes, 1998.

GORZ, André. Crítica da Divisão do Trabalho. 2.ed., Rio de Janeiro, Martins Fontes, 1989. KOSIK, Karel. Dialética do concreto. Rio de Janeiro: Paz e Terra, 1976. KUENZER, Acácia Zeneida. Desafios teórico-metodológicos da relação trabalho-educação e o papel social da escola. In: FRIGOTTO, G. (Org.) Educação e crise do trabalho: Perspectivas de final de século. Petrópolis, RJ: Vozes, 1998.

LEONTIEV, Alexei. O homem e a cultura. In: ADAM, Y. et al. $\mathbf{O}$ desporto e desenvolvimento humano. Lisboa: Seara Nova, 1977. 
MANACORDA, Mario Alighiero. Marx e a pedagogia moderna. São Paulo e Campinas, SP: Cortez: Autores Associados, 1991.

MARX, Karl. O capital: crítica da economia política. vol. I tomo I. São Paulo: Abril Cultural, 1983.

. Para a crítica da economia política; salário, preço e lucro; o rendimento e suas fontes: a economia vulgar. São Paulo: Abril Cultural, 1982. (Coleção Os Economistas)

MARX, Karl; ENGELS, Friedrich. A Ideologia Alemã. São Paulo, SP: Boitempo Editorial, 2007. . Manifesto do Partido Comunista 1848. Porto Alegre, RS: L\&PM, 2006.

MÉSZÁROS, István. Para além do capital. São Paulo, SP: Boitempo Editorial, 2002.

A educação para além do capital. São Paulo, SP: Boitempo Editorial, 2005.

. O desafio e o fardo do tempo histórico: o socialismo no século XXI. São Paulo, SP: Boitempo, 2007.

NOZAKI, Hajime Takeuchi. Educação Física e reordenamento no mundo do trabalho: mediação da regulamentação da profissão. 2004. 399p. Tese (Doutorado em Educação) - Faculdade de
Educação, Universidade Federal Fluminense, Rio de Janeiro, 2004. - Mundo do trabalho, formação de professores e conselhos profissionais. In: FIGUEIREDO, Z. C. C (Org.). Formação profissional em educação física e mundo do trabalho. Vitória, ES: Gráfica da Faculdade Salesiana, 2005. p.11-30.

PISTRAK, Moisey Mikhaylovich.

Fundamentos da escola do trabalho. São Paulo: Expressão Popular, 2000.

PONCE, Aníbal. Educação e luta de classes. 20 ed. São Paulo: Cortez, 2003.

SAVIANI, Dermeval. Escola e democracia: teorias da Educação, curvatura da vara, onze teses sobre a educação política. 36 ed. São Paulo: Autores Associados, 2003.

SOBRAL, F. A. da F. A produção e a apropriação social da pesquisa científica e tecnológica: uma discussão no capitalismo dependente. In: Revista Brasileira de Estudos Pedagógicos, Brasília, v. $67, n^{\circ} 156$, p. $287-305$, mai/ ago /1986.

SUCHODOLSKI, Bogdan. Fundamentos de pedagogia socialista. Barcelona: Laia, 1974. A Pedagogia e as Grandes Correntes Filosóficas. Lisboa: Livros Horizonte, 1984. 
SANTOS JÚNIOR, Cláudio de Lira. A formação de professores em Educação Física: a mediação dos parâmetros teóricometodológicos. 2005. 194p. Tese (Doutorado em Educação) - Faculdade de Educação, Universidade Federal da Bahia, Salvador, 2005.

TAFFAREL, Celi Nelza Zülke. A formação do profissional da educação: o processo de trabalho pedagógico e o trato com o conhecimento no curso de Educação Física. 1993. 302p. Tese (Doutorado em Educação) - Faculdade de Educação, Universidade Estadual de Campinas, Campinas, 1993.

TAFFAREL, Celi Nelza Zülke; et al. Uma proposição de Diretriz Curricular para a formação de professores de educação física. In: TAFFAREL, Celi Zulke; HILDEBRANDT-STRAMANN, Reiner (orgs). Currículo e Educação Física: formação de professores e prática pedagógica nas escolas. Ijuí: Ed. UNIJUÌ, 2007. p. 41-50

TAFFAREL, Celi Nelza Zülke; SANTOS JÚNIOR, Cláudio de Lira. Nexos e determinações entre formação de professores de educação física e diretrizes curriculares: competências para quê? In: FIGUEIREDO, Zenólia Christina Campos (Org.).
Formação profissional em educação física e mundo do trabalho. Vitória, ES: Gráfica da Faculdade Salesiana, 2005, p. 111-136.

VYGOSTKY, L. S. Pensamento e linguagem. São Paulo: Martins Fontes, 1987.

- A formação social da mente. São Paulo: M. Fontes, 1988. 


\begin{abstract}
The text deals with the pedagogical work in physical education in considering elements of the ontology of social being that allow us to explain how we became human beings throughout history and characteristics of immanent work. The scientific question concerns the possibility of changing trends inherent to the capitalist labor process in general, particularly in the pedagogical work, especially in physical education. The hypothesis is that there have been changes in the immanent tendencies of capitalist labor process, besides those analyzed by Marx, which puts us in the historic challenge of recognizing, in pedagogical work, its possibilities and tendencies, to interfere in them. The thread of the exposure part of the concept of motion, matter, activity, work and consciousness, considering certain modes of production - communal, Asian, feudal, capitalist - to get to the possibilities of work in general and in particular the pedagogical work . Empirical data come from physical education and supplies are the mediations in Bachelor of Physical Education of the university. The analysis carried out establish relationships and connections between the more general movement of capital and its laws and the peculiarities of the educational work, especially in physical education, indicating the current Defence Course Unified Extended Degree.
\end{abstract}

Keywords: Work. Educational Work. Physical Education.

Recebido: fevereiro/2011. Aprovado: abril/2011. 